\title{
Influence of Mode of Steroid Substrate Addition on Conversion of Steroid and Growth Characteristics in a Mixed Culture Fermentation
}

\author{
By B. K. LEE, W. E. BROWN, D. Y. RYU, H. JACOBSON
}

AND R. W. THOMA

The Squibb Institute for Medical Research, New Brunswick, New Jersey 08903, U.S.A.

(Accepted for publication 22 December 1969)

\section{SUMMARY}

The mode of addition of the steroid substrate, I $6 \alpha$-hydroxycortexolone I6, I7-acetonide, was shown to influence markedly the rate of enzymic conversion of the steroid as well as the form of growth of the fungal organism, in a mixed culture of Arthrobacter simplex (I-dehydrogenator) and Curvularia lunata (I $\beta$-hydroxylator). The effects observed were apparently related to the size and solubility of the steroid particles added in suspension or precipitated in the medium by addition of the steroid in any of several water-miscible non-aqueous solvents. The best rates of steroid conversion were observed when the mould grew in elongated pellets rather than in filamentous form.

\section{INTRODUCTION}

Shull (1959) and Kimura (1962) reported, respectively, on the multiple conversion of cortexolone to prednisolone by mixed cultures of Curvularia lunata and Mycobacterium phlei and of $C$. lunata and Bacillus sphaericus. Subsequently, we published a paper dealing with the bioconversion of $9 \alpha$-fluorohydrocortisone to I-dehydro-I $6 \alpha$ hydroxy- $9 \alpha$-fluorohydrocortisone (triamcinolone) by mixed cultures of Arthrobacter simplex and Streptomyces roseochromogenes (Lee, Ryu, Thoma \& Brown, 1969). In the present paper we report results obtained from the use of a mixed culture of Arthrobacter simplex (I-dehydrogenator) and $C$. lunata (I I $\beta$-hydroxylator) for the transformation of I6 $\alpha$-hydroxycortexolone I6,I7-acetonide to its I-dehydro-II $\beta$-hydroxy derivative, an intermediate in the synthesis of triamcinolone acetonide (Fig. I).<smiles>CC(=O)OC1CC2C3CCC4=CC(=O)CCC4(C)C3CCC2(C)C1(C(=O)CO)C(=O)CO</smiles>

$16 \alpha$-hydroxycortexolone 16,17 -acetonide

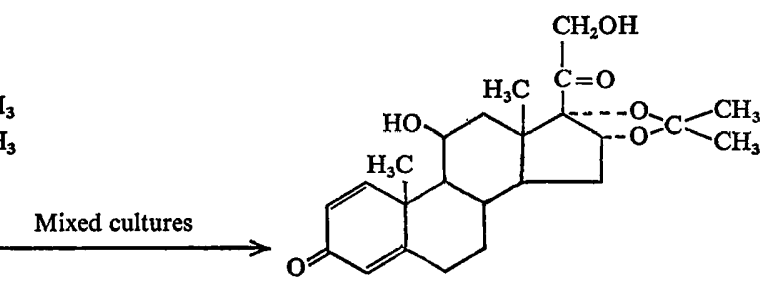

1-dehydro-11 $\beta$-hydroxy product

Fig. I. 
In the early stages of our studies we added the steroid substrate as a suspension in aqueous Tween 80 solution (polyoxyethylene sorbitan mono-oleate) and achieved a substrate concentration in the culture of not more than $250 \mu \mathrm{g} . / \mathrm{ml}$. Later, we found that, when we added the steroid in hot ethanol-water containing sodium tetraborate, we were able not only to increase the substrate concentration from 300 to $1000 \mu \mathrm{g}$. $/ \mathrm{ml}$., but also to shorten the time of the mixed-culture fermentation from I 20 to $72 \mathrm{hr}$. These results led us to compare still other methods of steroid addition. We found that the mode of addition of steroid substrate affects its solubility, and that there is a relationship between mode of addition, rate of bioconversion of steroid, and form of growth of the fungal organism in the pair.

\section{METHODS}

Organisms. Arthrobacter simplex (Squibb Culture 6062-v3) and Curvularia lunata (Squibb Culture 547I) were used. Arthrobacter simplex was maintained on yeast beefagar slants and Curvularia lunata on Gould agar slants. Stock cultures were stored over liquid nitrogen at $-150^{\circ}$.

Steroid substrate. 16 $\alpha$-Hydroxycortexolone I6, I7-acetonide used throughout the studies was a product of Syntex Laboratories, Mexico. The steroid substrate was suspended in cold (room temperature) $0.1 \%(w / v)$ aqueous Tween 80 or cold solvent, or dissolved in hot solvent; heating was effected by immersing a tube containing steroid and solvent in boiling water. Each suspension or solution of the substrate was made to a concentration of $100 \mathrm{mg}$. $/ \mathrm{ml}$. The hot borate + ethanol + water solution was made by combining $1240 \mathrm{mg}$. of the steroid substrate with $2 \cdot 29 \mathrm{ml}$. of aqueous sodium tetraborate solution $(62.5 \mathrm{mg}$. $/ \mathrm{ml}$.) and ethanol to a final substrate concentration of $100 \mathrm{mg} . / \mathrm{ml}$, and by heating the mixture gently until a clear solution was obtained.

Cultures. All cultures were grown in $100 \mathrm{ml}$. portions of medium in $500 \mathrm{ml}$. Erlenmeyer flasks and shaken at $25^{\circ}$ on a Gyrotory G-52 shaking machine (New Brunswick Scientific Co.) at $280 \mathrm{rev}$. $/ \mathrm{min}$. in a $2 \mathrm{in}$. diameter circle. The inoculum was grown in two $48 \mathrm{hr}$ stages. For the fermentation stages, portions ( $\mathrm{I} \mathrm{ml}$. and $5 \mathrm{ml}$. respectively) of vegetative cultures of Arthrobacter simplex and Curvularia lunata were used to inoculate $100 \mathrm{ml}$. of the broth. When the steroid substrate was added at $500 \mu \mathrm{g} . / \mathrm{ml}$. or less, substrate and organisms were added at zero time. When a total substrate concentration of $1000 \mu \mathrm{g}$. $/ \mathrm{ml}$. was used, the first portion of substrate $(500 \mu \mathrm{g} . / \mathrm{ml}$.) was added at zero time and the remainder after $24 \mathrm{hr}$ incubation.

Each organism was grown separately in two stages of E 33 and E 2 B medium or E 24 medium for both germination stages. For fermentation, the two organisms were mixed and grown in E 24 medium. E 33 medium contained (g./1. of medium) soybean meal (Archer-Daniels-Midland), I5; soybean oil, $2 \cdot 2$; glucose, II; $\mathrm{CaCO}_{3}, 2 \cdot 5 . \mathrm{E} 2 \mathrm{~B}$ medium was made of (g./1. of medium) Staley's soybean meal, 20; glucose, 30; soybean oil, 2.2; $\mathrm{CaCO}_{3}, 2 \cdot 5$. E 24 medium contained (g./1. of medium) cornsteep liquor, 6; glucose, $10 ; \mathrm{NH}_{4} \mathrm{H}_{2} \mathrm{PO}_{4}, 3$; Difco yeast extract, $2 \cdot 5 ; \mathrm{CaCO}_{3}, 2 \cdot 5$. All media were made with distilled water.

Preparation of samples for steroid measurement. Samples $(5 \mathrm{ml}$.) were drawn at intervals from the culture and each sample was extracted with $2 \mathrm{ml}$. of 4-methyl-2pentanone (methylisobutylketone, MIBK). 
Paper chromatography. Portions (0.I ml.) of MIBK extracts were spotted on Whatman no. I paper impregnated with propylene glycol and developed by descending chromatography with toluene saturated with propylene glycol.

Steroid measurement. Following development of the chromatograms, steroid spots were detected by ultraviolet scanning. The spots were marked with a tin-lead stylus, cut out, eluted with $95 \%(\mathrm{v} / \mathrm{v})$ ethanol, and the extinction of the extract measured at $240 \mu \mathrm{m}$. in a Beckman DU spectrophotometer. The concentration of steroid in each sample was then estimated using a standard solution equilibrated with MIBK and chromatographed in the same way as the samples.

Qualitative identification. Steroid spots were located by ultraviolet scanning and the papers sprayed with triphenyl-tetrazolium chloride (TTC). Steroids were then identified on the basis of mobility (Table I) and TTC reduction.

Centrifugation of samples for dissolution studies. Samples $(4.0 \mathrm{ml}$.) were taken at intervals, centrifuged for Io min. at $25^{\circ}$ at $39,900 \mathrm{~g}$ with a Sorval $\mathrm{RC}-2$ centrifuge (head type SM-24, 4.34 in.), and the steroid concentration was measured separately in the supernatant and precipitate from each sample.

Table I. Relative mobility values of steroids separated by paper chromatography in toluene-propylene glycol

\section{Steroid}

16 $\alpha$-hydroxycortexolone 16,17 -acetonide

I-dehydro-I $6 \alpha$-hydroxycortexolone I6, I 7-acetonide

I $\beta$, I $6 \alpha$-dihydroxycortexolone I6, I7-acetonide

I-dehydro-I I $\beta$, I $6 \alpha$-dihydroxycortexolone I6, I7-acetonide
Relative mobility

$\left(R_{F}\right)$

$0 \cdot 8 \mathrm{I}$

0.67

0.30

$0 \cdot 15$

Preparation of slides and photographs of crystals of I6 -hydroxycortexolone I6,I7acetonide. I $6 \alpha$-Hydroxy-cortexolone $\mathrm{I} 6, \mathrm{I} 7$-acetonide $(300 \mu \mathrm{g} . / \mathrm{ml}$.) was added to the supernatant of E 24 medium in cold Tween 80 suspension, in hot ethanol and in hot borate + ethanol + water, and mixed well by shaking. Slides were prepared (wet with no stain), and photographs were taken at a magnification of $\times 430$, with Polaroid black and white/3000 speed film (type 107).

Particle-size analysis. A Coulter Counter (model B) was used to measure particlesize distributions in artificial systems (Fig. 2), because similar analyses on cultures presented major difficulties. It was believed that information gained from the artificial systems would be indicative of occurrences in the fermentation. Consequently the steroid was suspended in a prefiltered solution containing $0.1 \%(\mathrm{w} / \mathrm{v})$ Tween 80 and I $\%(w / v)$ sodium chloride (the latter being a requirement for operation of the counter). The $400 \mu \mathrm{m}$. aperture tube that was used is capable of detecting particles 6 to $200 \mu \mathrm{m}$. in diameter. Analyses were also made of suspensions resulting from the addition of solutions of the steroid in hot ethanol and in hot borate + ethanol + water to appropriate amounts of prefiltered I \% sodium chloride solutions. The concentration of steroid in the resultant suspensions was $500 \mu \mathrm{g}$. $/ \mathrm{ml}$. Samples were withdrawn and analysed using a $30 \mu \mathrm{m}$. aperture tube capable of measuring particles 0.6 to $15 \mu \mathrm{m}$. in diameter. 


\section{RESULTS \\ Effects of the mode of substrate addition on steroid conversion}

The multiple conversion of I $6 \alpha$-hydroxycortexolone I6, I 7 -acetonide to its I-dehydroII $\beta$-hydroxy derivative was followed under conditions in which the substrate was charged, in two portions of $500 \mu \mathrm{g}$. $/ \mathrm{ml}$. each at zero time and $24 \mathrm{hr}$, in various forms. The conversion obtained with each form of substrate addition was, in descending order of efficiency, hot borate + ethanol + water solution $(90 \%)$, hot ethanol + acetone solution $(67 \%)$, hot ethanol solution $(65 \%)$, cold dimethylformamide (DMF) solution $(60 \%)$, cold ethanol+acetone suspension $(30 \%)$, cold ethanol suspension $(20 \%)$, and cold aqueous Tween suspension (I0 \%) (Fig. 3). When the substrate solubilized in hot solvents (borate + ethanol + water, ethanol + acetone, ethanol) or in cold DMF was added to the culture, it precipitated immediately. The resultant precipitates appeared to be different in crystal form and size from the 'raw' or original material added in cold aqueous Tween suspension. When added in solution, in general, the substrate was dispersed in forms much finer than that of the original crystalline material (Pl. I, fig. I, 2, 3). Thus, more surface area was provided for contact with cells and for dissolution.

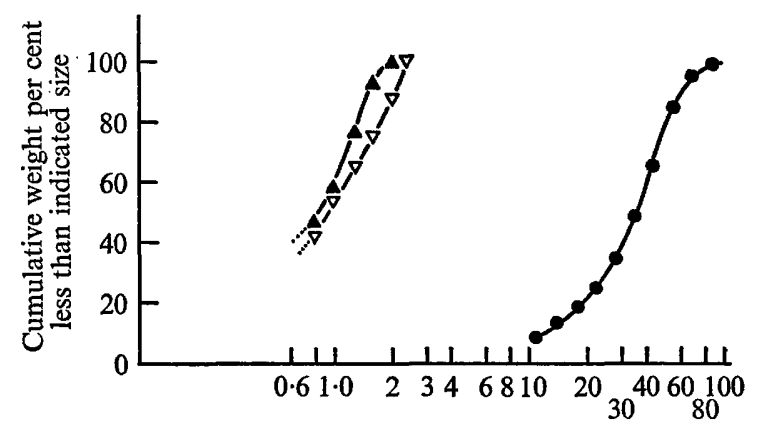

Equivalent spherical diameter ( $\mu \mathrm{m}$.)

Fig. 2

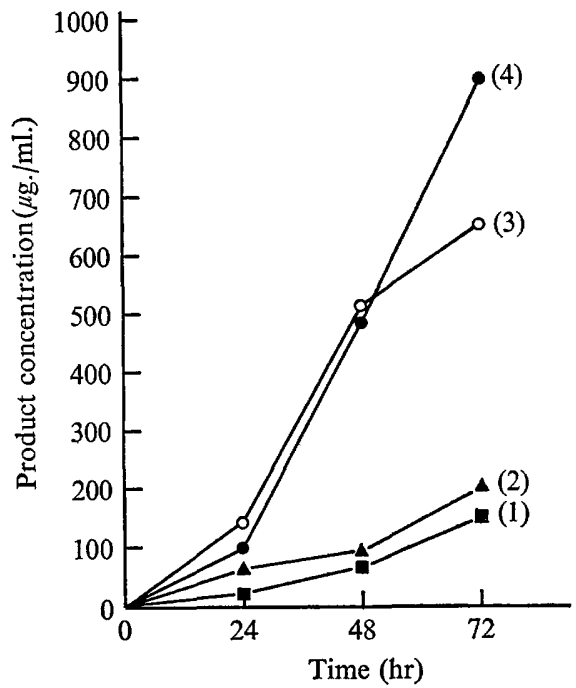

Fig. 3

Fig. 2. Particle-size distribution as determined by the Coulter counter. $\boldsymbol{\Delta}$ indicates data from particles generated by addition of a hot ethanol solution of steroid to a prefiltered solution containing $0.1 \%(\mathrm{w} / \mathrm{v})$ Tween 80 and $\mathrm{r} \%(\mathrm{w} / \mathrm{v})$ sodium chloride; $\nabla$, particles generated by addition of a hot ethanol + borate + water solution of steroid to the prefiltered solution; , particles obtained by addition of steroid suspension to the prefiltered solution.

Fig. 3. Effects of the mode of substrate addition on the multiple transformation of $16 \alpha-$ hydroxycortexolone 16,17 -acetonide to the I-dehydro-I $\beta$-hydroxy product by a mixed culture of Arthrobacter simplex and Curvularia lunata. Each of the organisms was separately germinated in E 24 medium and then grown in the same medium with the steroid substrate added in different forms. (I) indicates final product formed when the steroid substrate was added in cold Tween suspension; (2), final product formed when the steroid substrate was added in cold ethanol suspension; (3), final product formed when the steroid substrate was added in hot ethanol solution; (4), final product formed when the steroid substrate was added in hot borate + ethanol + water solution. 
Borate was tested in several concentrations in the mixture. Fig. 4 shows three productivity curves obtained with 3,30 , or $90 \mu$ mole of borate $/ 100 \mathrm{ml}$. of culture broth. In each case, $\mathrm{I} \cdot 0 \mathrm{ml}$. of stock solution was added to $\mathrm{I}$ oo $\mathrm{ml}$. of culture broth. From these curves it is seen that $30 \mu \mathrm{mole} / 100 \mathrm{ml}$. was better than the higher or lower concentrations. However, when $30 \mu$ mole of borate $/ 100 \mathrm{ml}$. was added separately from the appropriate amounts of suspended steroid and ethanol, the productivity was much lower (Fig. 4, curve 4).

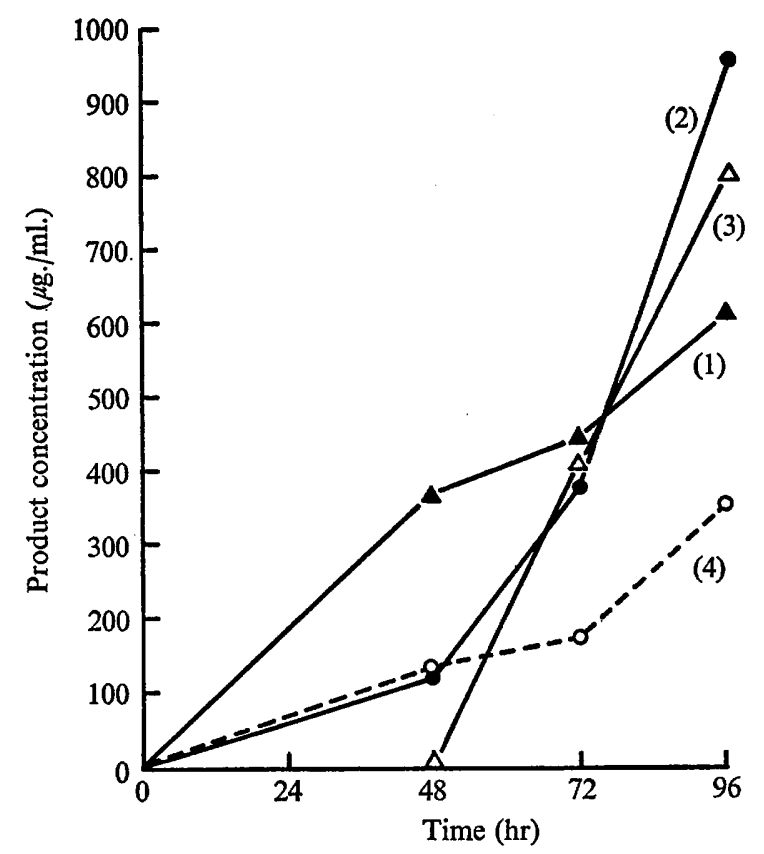

Fig. 4. Productivity, in the multiple conversion of $16 \alpha$-hydroxycortexolone 16,17 -acetonide to $\mathrm{I}$-dehydro-I I $\beta, \mathrm{I} 6 \alpha$-dihydroxycortexolone $\mathrm{I} 6, \mathrm{I}$ 7-acetonide, from different concentrations of borate. (I) From $3 \mu$ mole of borate incorporated in the solubilized stock solution of steroid substrate + borate + ethanol + water; (2) from $30 \mu$ mole of borate, as (I); (3) from $90 \mu$ mole of borate, as (I); (4) from $30 \mu$ mole of borate added separately following separate addition of steroid substrate and of ethanol into the medium.

\section{Effects of mode of substrate addition on growth characteristics}

The differences in the effects of the mode of substrate addition on growth characteristics of the fungal organism mixed in the pair were also striking. Cold Tween suspension resulted in a tan filamentous type of growth, cold ethanol suspension in tan granular-filaments, hot ethanolic solution in brown elongated pellets, cold ethanol+ acetone suspension in brown granular filaments, hot ethanol+acetone solution in brown-black elongated pellets, hot borate + ethanol + water solution in black elongated pellets, and cold DMF solution in brown granular filamentous growth mixed with elongated pellets (P1. 2). As a general rule, the elongated pellet form of growth was more often associated with higher conversion than was the filamentous type of growth.

The appearance of the untreated control culture was tan granular-filaments, indistinguishable from the culture treated with steroid in Tween suspension. Moreover, 
the appearance of the culture was not modified when $30 \mu$ mole of borate/100 $\mathrm{ml}$. culture broth and the appropriate amounts of ethanol and steroid in suspension were added separately.

No change in the morphology of Arthrobacter simplex due to steroid solution or suspension was detected.

\section{Solubility studies}

The solubility of $16 \alpha$-hydroxycortexolone $\mathrm{I} 6,17$-acetonide, added at $500 \mu \mathrm{g} . / \mathrm{ml}$. in cold aqueous Tween suspension and in hot borate + ethanol+water solution, were
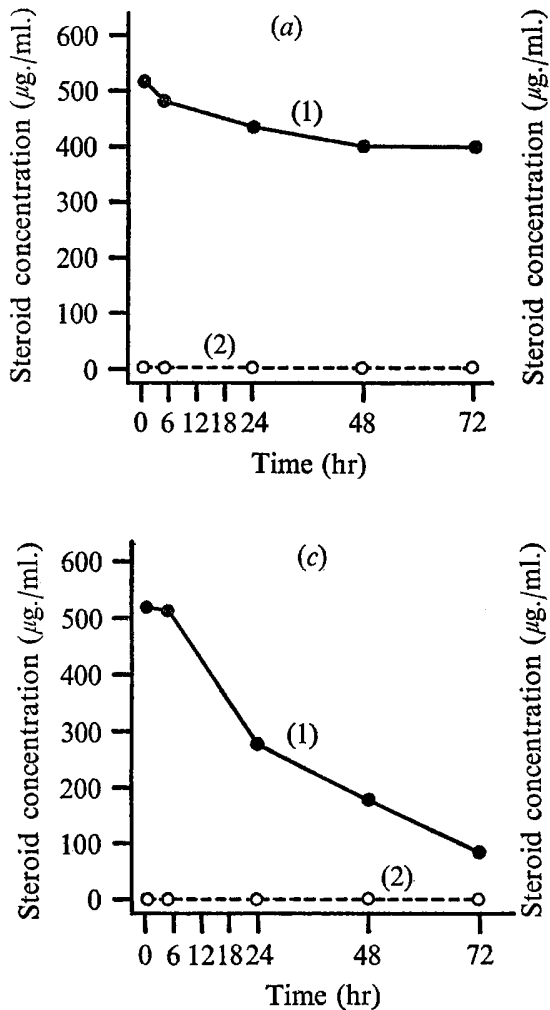

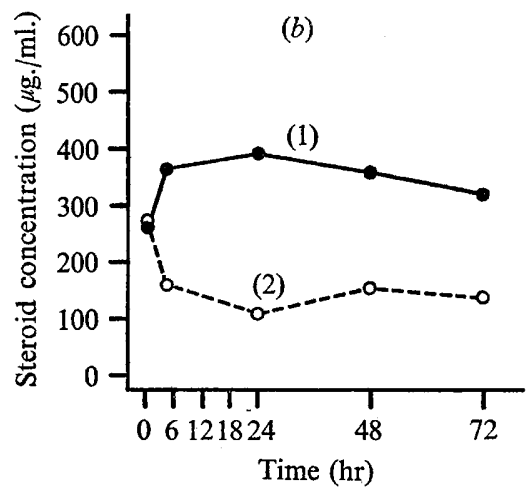

(d)

Fig. 5(a). Dissolution rate of $16 \alpha$-hydroxycortexolone 16,17 -acetonide added in cold Tween suspension into E 24 medium minus organisms. (I) indicates the steroid concentration in precipitate (undissolved steroid); (2), the steroid concentration in supernatant (dissolved steroid).

Fig. $5(b)$. Dissolution rate of $16 \alpha$-hydroxycortexolone 16,17 -acetonide added in hot borate + ethanol + water solution into E 24 medium minus organisms. (I) indicates the steroid concentration in precipitate (undissolved steroid); $(2)$, the steroid concentration in supernatant (dissolved steroid).

Fig. 5(c). Dissolution rate of I $6 \alpha$-hydroxycortexolone I6, I 7-acetonide added in cold Tween suspension into E 24 medium including the mixed culture of Arthrobacter simplex and Curvularia lunata. (I) indicates the steroid substrate concentration in precipitate (undissolved steroid substrate); (2), the steroid substrate concentration in supernatant (dissolved steroid substrate).

Fig. $5(d)$. Dissolution rate of $16 \alpha$-hydroxycortexolone 16,17 -acetonide added in hot borate + ethanol+water solution into E 24 medium including the mixed culture of Arthrobacter simplex and Curvularia lunata. (I) indicates the steroid substrate concentration in precipitate (undissolved steroid substrate): (2), the steroid substrate concentration in supernatant (dissolved steroid substrate). 
followed in the cornsteep liquor medium (E 24) with and without the mixed cultures of Arthrobacter simplex and Curvularia lunata. The solubility of the steroid substrate added in cold Tween suspension was negligible as compared to that added in hot borate + ethanol + water solution (Fig. $5 a, b$ ). When added in cold Tween suspension, the substrate was slowly transformed by the mixed culture without any substrate in solution being detectable. A substantial amount of the substrate was left untouched up to $72 \mathrm{hr}$ incubation (Fig. $5 \mathrm{c}$ ). On the other hand, the substrate added in hot borate + ethanol + water solution was dissolved, up to $280 \mu \mathrm{g} . / \mathrm{ml}$., in less than $30 \mathrm{~min}$. Faster conversion was observed and no trace of the substrate was seen either in the supernatant or in the precipitate of the culture filtrate at or after $24 \mathrm{hr}$ (Fig. $5 d$ ). Thus, the results show a direct relationship between solubility of the substrate and the rate of steroid conversion.

\section{Particle-size studies}

The particle-size distributions as measured by the Coulter counter are shown in Fig. 2. The lowest dimension that could be measured with the counter was $0.6 \mu \mathrm{m}$., and it can be presumed that smaller particles were present. However, the data clearly show the large differences that result when the steroid is added directly as a suspension and when the steroid is first dissolved in a limited volume of solvent and then added to an aqueous system. The range of particle sizes obtained by use of a hot borate + ethanol + water solution is slightly greater than that obtained by use of a hot ethanol solution (Pl. I, fig. 2, 3). Even though these results were obtained using an artificial system, we have good reason to believe that the results are representative of the situation in the culture. The appearance of crystals in the culture supports the particlesize data as do the more detailed photomicrographs (Pl. I, fig. I, 2, 3).

\section{DISCUSSION}

Weaver et al. 1960 \& Weaver (1962), used Rhizopus nigricans or Aspergillus ochraceus and carried out I $\alpha$-hydroxylation of progesterone by adding the steroid substrate in the original 'raw' form and in a ground 'smooth' form, and found, at a concentration of $50 \mathrm{~g}$. progesterone $/ 1 ., 65 \%$ and $40 \%$ conversion, respectively, from ground and unground substrate. He postulated that, by grinding the substrate, not only was the organism provided with a smooth non-injurious surface, but a higher degree of interfacial contact between the substrate particles and the organisms was obtained.

Our data clearly show that the rate of steroid bioconversion is much influenced by the mode of steroid substrate addition. A relatively rapid rate is obtained when the steroid concentrate is added as a solution, notwithstanding the immediate precipitation that occurs upon its addition to the culture. Clearly, in this instance more of the steroid substrate is available to the organisms than when a relatively coarse suspension is added.

The enhanced availability is directly related to the markedly greater solubility of the resultant fine suspension than that of the coarse material (Fig. 5a,b). It is known that fine particles are more soluble than relatively coarse ones. Furthermore, the material that precipitates appears by microscopic observation to be amorphous (P1. I, fig. 2, 3), and it is also well known that different polymorphic forms have different solubilites, the amorphous forms often being considerably more soluble than a crystalline form. The existence of the amorphous form is also supported by the 
failure of the fine suspension obtained in the artificial system to rotate polarized light, whereas the coarse suspension does.

Both phenomena are metastable. With time the coarse particles will grow at the expense of the fine, and the more stable polymorphic species will form at the expense of the less stable species. However, the greater solubility persists for at least $72 \mathrm{hr}$ in fine suspension (Fig. 5 b).

In addition to the aforementioned solubility effect, the fine particles also have a more rapid dissolution rate. In the presence of the organisms that are utilizing dissolved steroid, replenishment of dissolved steroid is very rapid from the fine suspension (Fig. $5 d$ ). With the coarse suspension the amount of steroid in solution is low and practically at a steady state (Fig. $5 c$ ).

Growth characteristics of the fungal organism in the pair were also influenced by the mode of steroid substrate addition. In general, pellet and filamentous forms of growth were brought about, respectively, by addition of the steroid in solution and in suspension. When the steroid and an appropriate amount of solvent were added separately to a single flask containing inoculated medium, the filamentous form of growth was observed, as in the case of adding the steroid in suspension. Further, different means of steroid addition did not have any significant effect on the $\mathrm{pH}$ value of the growth medium. Thus, neither solvent nor $\mathrm{pH}$ value was a factor in directly altering the changes in growth of the fungal organism. Apparently the differences in growth characteristics observed are related to the differences in size and shape of the steroid particles that result from the different modes of substrate addition. One would expect the large crystals to have a different abrasive effect on the fungal mycelium as it grows than do the smaller particles. Possibly this then is the reason for the development of the filamentous and pellet types of mycelium in the presence of large crystals and small particles, respectively.

We believe that the greater rate of steroid transformation is related not only to the greater solubility and more rapid dissolution of the substrate but also to the presence of the pellet form of fungal mycelium. The latter being more dispersed than the filamentous form provides a greater surface area and thereby greatly enhances the contact between organism and steroid.

It is to be noted from Fig. 4 that the initial rates of conversion are inversely proportional to the amounts of borate used. This observation implies that borate is toxic to at least one of the organisms. At $30 \mu$ mole borate/100 ml. culture broth, delayed transformation is observed during the initial phase of the fermentation. This initial toxic effect is then apparently overcome, since a rapid rate of conversion is eventually achieved.

The observation that use of borate + ethanol + water for solubilization makes possible continuing rapid conversion beyond $48 \mathrm{hr}$ as contrasted to the use of ethanol alone is of interest (Fig. 3, curves 3 and 4). Since essentially only intermediates and final product are present after $48 \mathrm{hr}$, it is conjectured that the presence of borate maintains the permeability of the organisms to the intermediates and that, as a consequence, a high rate of conversion is maintained. In the absence of borate the organisms may lose permeability with age and the conversion slow down. However, no experimental data have been obtained to support these speculations. 
Journal of General Microbiology, Vol. 6r, No. I

Plate I
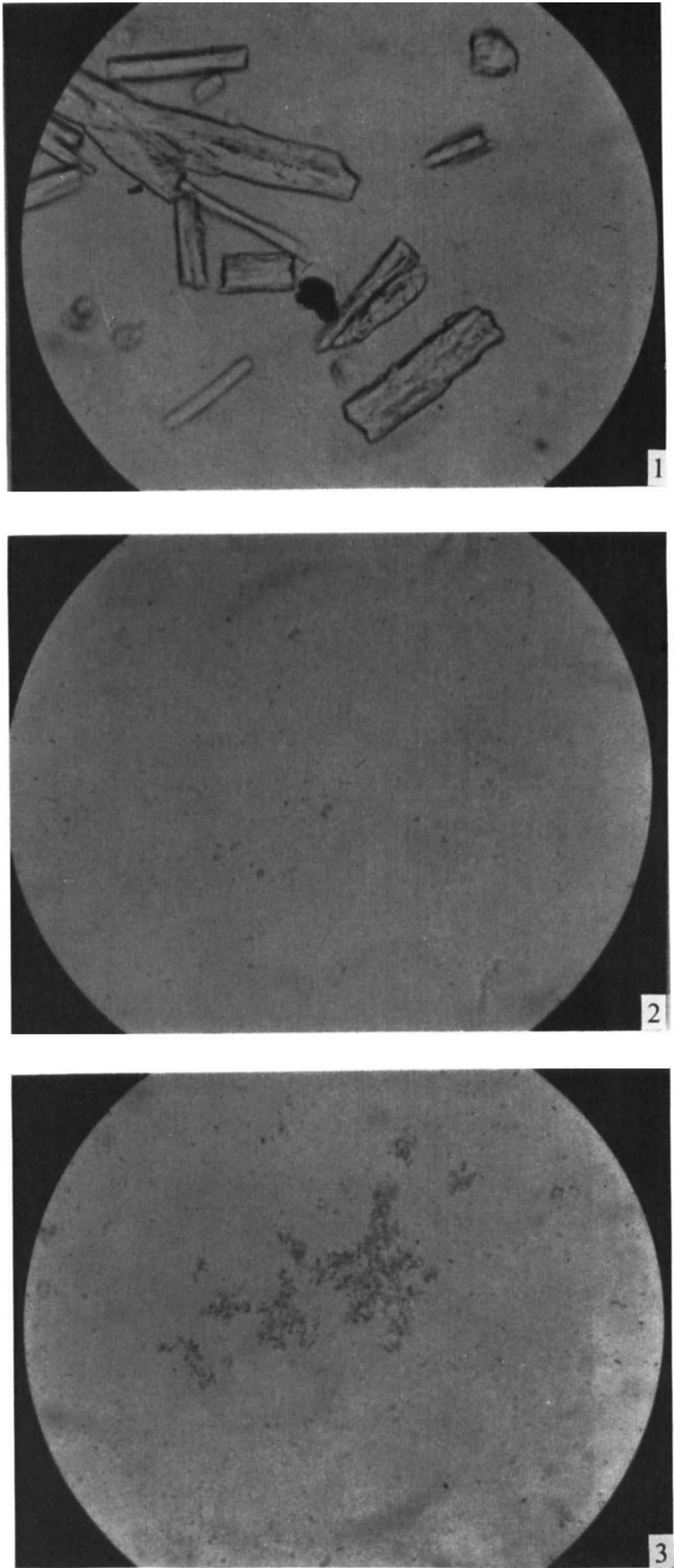

B. K. LEE AND OTHERS

(Facing p. 104) 
Journal of General Microbiology, Vol. 6I, No. I

Plate 2

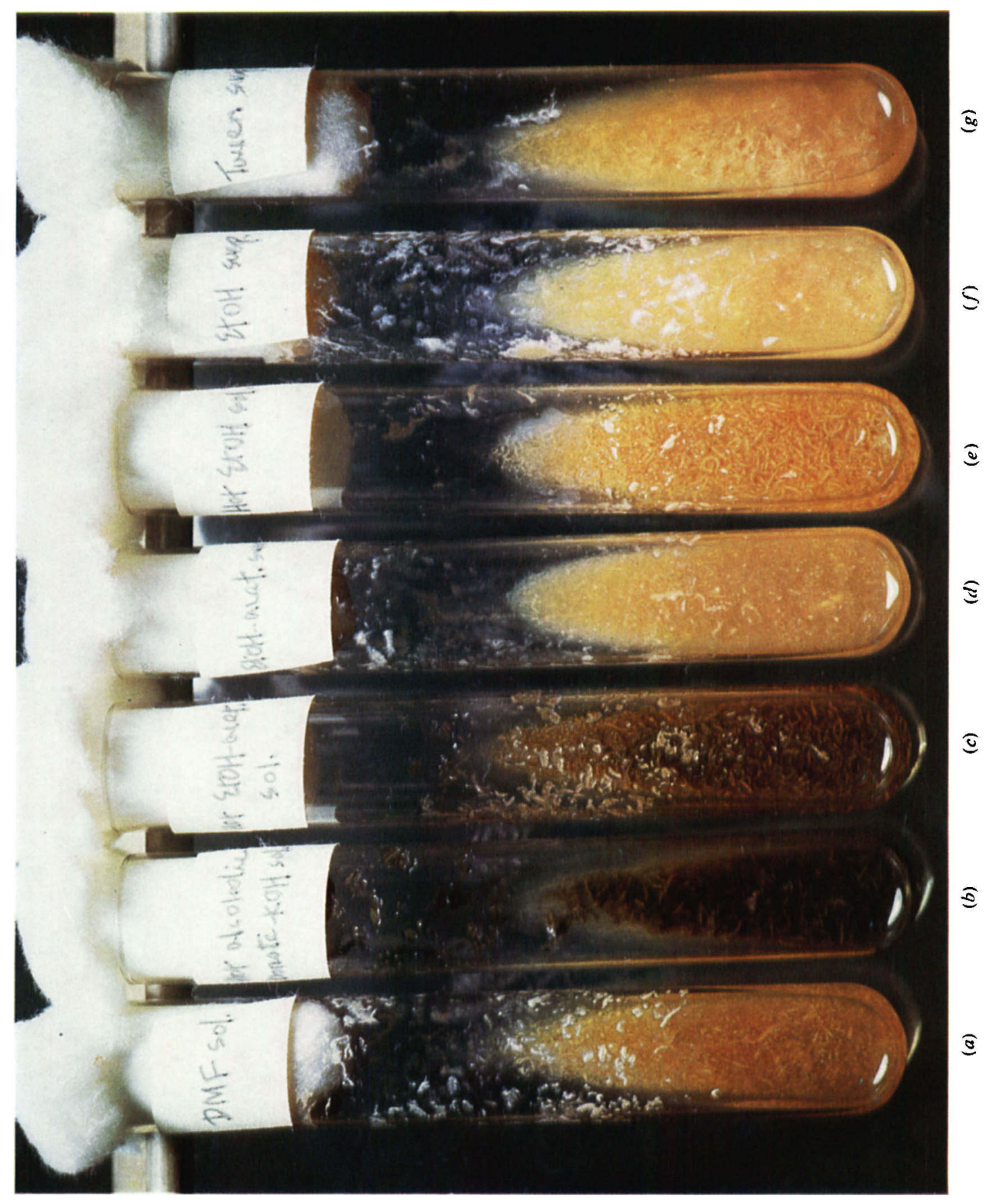

B. K. LEE AND OTHERS 


\section{REFERENCES}

KIMURA, T. (1962). On the transformation of Reichestein's substance $S$ to prednisolone with the co-operative action of fungi and bacteria. Shionogi Research Laboratory Report 12, I80.

Lee, B. K., Ryu, D. Y., Thoma, R. W. \& Brown, W. E. (1969). Induction and repression of steroid hydroxylases and dehydrogenases in mixed culture fermentations. Journal of General Microbiology 55, 145 .

Shull, G. M. (1959). Verfahren zur Herstellung von Prednisolone. German Patent 1,050,335.

Weaver, E. A. (1962). Method of increasing microbial activities. U.S. Patent 3,019, 170.

WeAVER, E. A., KenNEY, H. E. \& WALL, M. E. (1960). Effect of concentration on the microbiological hydroxylation of progesterone. Applied Microbiology 8, 345 .

\section{EXPLANATION OF PLATES}

Plate I

Fig. I. Photomicrograph of crystals of $16 \propto$-hydroxycortexolone 16,17 -acetonide seen immediately after addition of cold Tween-80 suspension to the supernatant of E 24 medium. $\times 430$.

Fig. 2. Photomicrograph of crystals of $16 \alpha$-hydroxycortexolone 16,17 -acetonide seen immediately after addition of solution in hot ethanol to the supernatant of E 24 medium. $\times 430$.

Fig. 3. Photomicrograph of crystals of $16 \alpha$-hydroxycortexolone 16,17 -acetonide seen immediately after addition of solution in hot borate + ethanol + water mixture to the supernatant of E 24 medium. $\times 430$.

\section{Plate 2}

Effects of the mode of the steroid substrate addition on growth characteristics of the fungal organism in the pair (Arthrobacter simplex and Curvularia lunata). The figure shows photographs looking downward on samples taken from $72 \mathrm{hr}$ shaken flask cultures, placed in test-tubes, and propped at a low angle for better visualization: $(a)$ addition in cold dimethylformamide solution resulted in a brown granular filamentous form of growth mixed with elongated pellets; $(b)$ addition in hot borate + ethanol+water solution resulted in black elongated pellets; (c) addition in hot ethanol+acetone $(\mathrm{I}+\mathrm{I})$ solution resulted in brownish-black elongated pellets; $(d)$ addition in cold ethanol+acetone suspension resulted in a brown granular filamentous form of growth; (e) addition in hot ethanol solution resulted in brown elongated pellets; $(f)$ addition in cold ethanol suspension resulted in a tan granular filamentous form of growth; $(g)$ addition in cold Tween suspension resulted in a tan filamentous form of growth. 